\title{
The Analysis of Negative Effects Brought by Internet Economy under New Economic Normality
}

\author{
Wang Huiqing ${ }^{1, a,{ }^{*}}$
}

${ }^{1}$ The Institute of new business pattern, Shandong Management University, Jinan, Shandong, China ahq601182@163.com

Keywords: New Economic Normality, Internet Economy, Negative Effects, Supervision.

\begin{abstract}
Under the background of the new economic normality, internet has been infiltrating through each industry, which promotes the appearance and development of internet economy. The developing internet economy has dramatically positive effects on transforming domestic traditional industry as well as upgrading industrial structure. However, with the occurrence of some bad news, such as "WeiZexi event" and "Eleme Black workshop", the negative influence brought by internet economy on customers, social environment and other aspects should not be ignored. According to internet economy, we not only confirm its success, but also discover the problems and positively find the solutions, which is likely to obtain more results. Therefore, this article firstly defines the meaning of internet economy and analyses the status of its development. Secondly, the intention of negative effects of internet economy would be identified, and its reason would be demonstrated as well. Finally, the relative advice would be given at the end of this paper.
\end{abstract}

\section{新常态下互联网经济的负面效应分析 \\ 王惠庆 ${ }^{1, a,{ }^{*}}$ \\ 1新兴业态研究所, 山东管理学院, 济南, 山东, 中国 ahq601182@163.com}

关键词: 新常态; 互联网经济; 负面效应; 监管

摘要. 经济新常态背景下, 互联网正在向各个行业全面渗透, 促使互联网经济的产生和壮大。 互联网经济的发展对我国传统行业改造、产业结构调整升级等方面起到积极作用，甚至互联 网被称为是引领经济发展的新引擎。然而, 伴随着互联网经济而来的 “魏则西事件”、“饿 了么黑心作坊事件” 等不断发生，互联网经济对消费者、社会环境等方方面面造成的不良影 响更应该引起我们的重视。只有在肯定成绩的同时, 重视问题的存在, 并积极寻求解决问题 的方法, 才能取得更好的成绩。因此, 本文首先界定互联网经济的内涵, 并分析我国互联网 经济的发展现状; 然后界定互联网经济负面效应的内涵, 并分析其产生的原因; 最后提出相 应的对策建议。

\section{1. 引言}

近年来我国经济发展呈现出新的常态，在此背景下互联网正在向各个行业全面渗透，我 们迎来了互联网经济时代。近年来, 我国互联网的覆盖面迅速扩大, 以网民规模和互联网普 及率的持续增长为例, 截至 2016 年 6 月, 中国网民规模达 7.1 亿, 互联网普及率达到 $51.7 \%$, 与 
2015年底的 6.88 亿和 $50.3 \%$ 相比均有明显增长。 ${ }^{1}$ 互联网对国民日常工作和生活的影响逐步深 化, 促使各个传统行业领域纷纷拥抱互联网寻找新动力、开辟新领域, 由此催生了许多新业 态、新模式。面对互联网对传统经济领域的扰动, 政府采取了鼓励创新、优化治理和战略扶 持的态度。2015年各级政府先后出台了众多推进 “互联网+”发展的相关政策，“互联网+” 被上升到国家战略的高度, 各个行业各个领域纷纷加入到 “互联网+” 的践行大军之列。我国 互联网经济规模及其在GDP中的占比均呈现持续增长态势, 据2014年麦肯锡发布的《中国的数 字化转型：互联网对生产力与增长的影响》报告称, 互联网经济在GDP中的占比年增长率为 0.3\%，2014年底已达 7\%, 预计到 2025 年增长到 $10 \%-25 \%$, 相当于 4 万亿-14万亿元的年GDP总量。 互联网经济的发展的确已经在改造传统行业、调整产业结构和促进产业转型升级等方面取得 了一定的成功, 为国民经济增长做出了巨大贡献, 甚至被称为是引领经济发展的新引擎。然 而, 伴随着互联网经济而来的 “魏则西事件”、“饿了么黑心作坊事件” 等不断发生, 互联 网经济对消费者、社会环境等方方面面造成的不良影响（负面效应）更应该引起我们的重视。 只有在肯定成绩的同时, 重视问题的存在, 并积极寻求解决问题的方法, 才能取得更好的成 绩。因此, 本文首先界定互联网经济的内涵, 并分析我国互联网经济的发展现状; 然后界定 互联网经济负面效应的内涵，并分析其产生的原因；最后提出相应的对策建议。

\section{2. 互联网经济内涵及发展现状}

\section{1 互联网经济的内涵界定}

随着信息技术的不断发展和互联网技术的不断普及，经济主体的生产、交换、分配、消 费等经济活动越来越多地依赖信息网络, 互联网已经深深的融入了人们的日常生活。近年来, 我国传统行业互联网化、互联网创新创业开展的如火如茶, 互联网正在成为经济增长的新引 擎, 由此我们进入了一个互联网经济时代。互联网经济是信息化、网络化时代经济发展的必 然趋向。所谓互联网经济是指各传统行业和传统领域紧密结合互联网技术, 改变传统的生产 组织方式、要素分配方式、产品供给形态和商业服务模式, 实现组织创新、产品创新、产业 创新、模式创新的新型经济形态。

\section{2 我国互联网经济的发展现状}

近年来, 我国的经济发展已经呈现出一种新的常态, 主要体现在互联网经济下的技术创 新、行业转型升级、新产业新模式的创新。行业互联网化的应用场景不断细分裂变, 商业模 式不断创新, 服务经济已经超过工业经济占据主导地位, 移动互联网广泛应用于传媒、通讯、 出租车、金融等传统行业, 其市场规模呈现出井喷式增长。 ${ }^{2}$ 互联网经济下几乎所有传统行业 传统领域都或多或少的呈现出了新业态、新模式, 本文仅选取其中较为突出的互联网金融、 电子商务、新兴服务业等三大领域进行研究, 总结这三大领域的发展现状。

\subsection{1 互联网金融的发展现状}

近年来，我国互联网基础设施不断完善、普及率不断提高，对传统金融行业产生了巨大 的冲击，传统金融行业借助互联网技术，在国家推动 “互联网+” 发展的大环境下，互联网金 融在我国蓬勃兴起并取得了爆炸式的发展。 ${ }^{3}$ 所谓互联网金融, 从狭义上讲是指传统金融服务

\footnotetext{
1 数据来自中国互联网络信息中心 (CNNIC) 发布的第38次《中国互联网发展状况统计报告》。

2 2001年至2013年间第三产业增加值占GDP的比重年均实际增长 $10.6 \%$ ；2013年达到 $46.1 \%$ ；2014年达到 $48.2 \%$; 2015 年上半年进一步提升到了 $49.5 \%$ 。2014年中国移动互联网用户数达 7.3 亿人, 较上年增长 $11.8 \%$, 市场规模达 13437.7 亿元, 增长 $183.8 \% ; 2015$ 年用户数预计达到 7.9 亿人, 与 2014 年相比增长 $8.4 \%$, 市场规模达 23134.3 亿元, 增幅达到 $72.2 \%$ — 《2016年中国移动互联网用户分析》。

3 截至2016年8月底, 已检测到的互联网金融平台达到8490家，互联网金融活跃用户达到6.18亿户。截至2016年6 月, 中国网民规模达7.10亿，互联网金融用户占中国网民的比例已达到 $87 \%$ 。一 《中国互联网金融发展报告 2016》, http://mt.sohu.com。
} 
通过或依托互联网技术来实现资金融通的新方式方法; 从广义上讲，是指与互联网相结合的 金融新业态。现阶段, 我国互联网金融的发展过程中先后出现了六种模式: 传统金融业务的 互联网化、第三方支付、P2P网贷、众筹融资、新型电子货币和网络金融服务平台（王明国， 2015)。

传统金融业务互联网化的模式主要有：网上转账、网上投资理财、网上资金借贷、网上 证券和保险交易等。《互联网金融报告2016: 传统金融的互联网化》指出, 银行业务互联网 化主要有网络银行、直销银行、手机银行等模式; 证券业务互联网化的推进主要通过自建电 商平台、进驻第三方电商平台和独立第三方网站等模式; 基金业务互联网化的开展主要通过 第三方支付平台、基金超市、网上银行销售和基金公司网上直销等方式; 保险业务互联网化 的开展主要通过官网直销、专业的第三方保险销售网站、众安在线、电子商务平台等方式; 信托业务开展互联网化的主要模式有信托直销和债权转让机制下信托受益权拆分转让。 ${ }^{4}$ 随着 电子商务的不断发展, 获得第三方支付牌照的企业数量及其市场规模均有明显增长。国内获 得第三方支付牌照的企业由2011年5月第一批仅有的27家稳步增至2015年3月的270家; 第三方 支付市场的交易规模由 2011 年的 8.4 万亿元逐年稳步增长至2015年的 31.2 万亿元。我国P2P网 贷拥有多元化的服务模式, 主要有无担保模式、有担保模式、纯线上模式、线上线下相结合 模式、纯平台模式、债权转让模式等。由于P2P小额信贷具有覆盖面广、贷款高效快捷等优势, 我国P2P网贷的企业数量及其市场规模均有大幅增长, 我国P2P网贷的企业数量由 2009 年的91 家增至 2015 年的 3600 家; 市场规模也由 2009 年的1.5亿元增长到了 2015 年的 1000 亿元。自 2014 年开始, 我国众筹平台的数量和市场规模均有显著增长, 2014年新增众筹运营平台142家实现 市场规模15亿，截止2015年平台数量超过280家实现市场规模100亿元。

\subsection{2 电子商务的发展现状}

随着互联网的普及和智能手机的发展，在国家 “互联网+”相关政策的支撑引导下，越来 越多的企业采用电子商务推动自身产品的扩展, 我国人民选择以电子商务平台实现购物的人 群整体呈现逐年上升趋势。近年来, 随着我国电子商务的不断发展, 表现为市场交易额持续 快速增长（见图1），服务模式多元化（如B2B、B2C、C2C、020等），向农村、国外以及移动 端等三大领域进军的态势。

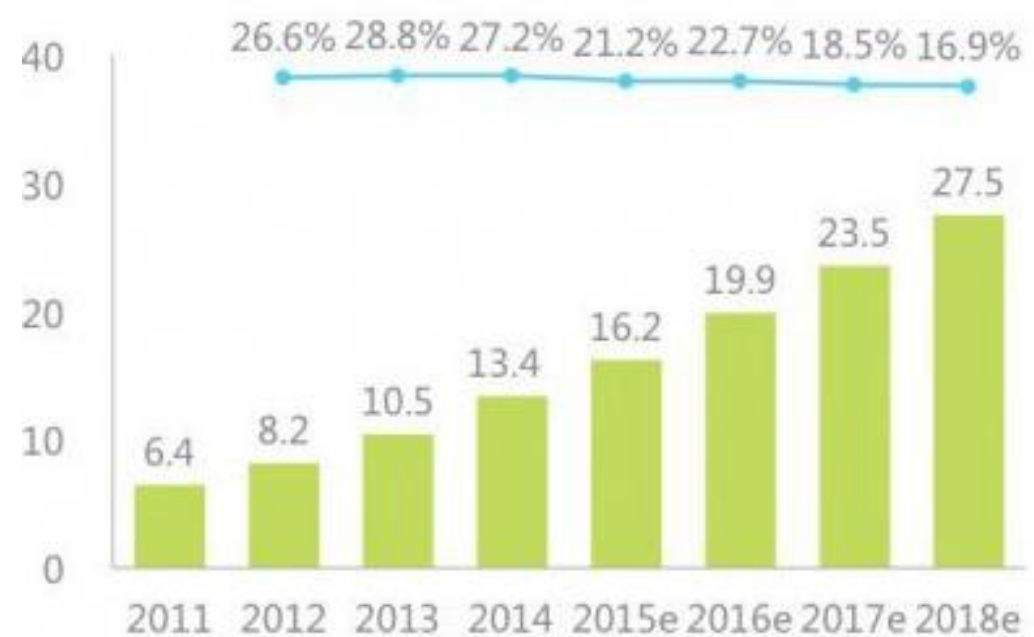

国中国电子商务市场交易规模 (万亿元)

一增长率 $(\%)$

图1２011-2018中国电子商务市场交易规模 来源：2015年度艾瑞咨询报告

\footnotetext{
${ }^{4}$ 2013年第三季度以来, 23家上市券商中有 18 家券商都大力加码互联网证券业务; 2015年上半年, 中国通过互 联网渠道销售的保险累计保费收入 816 亿元，是上年同期的 2.6 倍，占行业总保费的 $4.7 \%$, 这一收入已接近 2014 年互联网保险全年的保费水平; 截至2015年底，全国已有57家商业银行上线了直销银行。
} 
企业间B2B模式的电子商务所占比例有所下降但仍超七成，其交易规模持续增长; 网络购 物与 020 在电商市场中所占比例稳步提升, 成为拉动电子商务整体增长的新动力。2015年, 企 业间B2B市场交易规模达 11.8 万亿元，占全国电子商务市场交易规模的 $71.95 \%$ ，但其增长速度 （18\%）较全国的低4.7个百分点; 网络市场交易规模较 2014 年提高了 $37.2 \%$, 达到 3.8 万亿元, 其中B2C市场交易规模的占比高达 $52.2 \%$, 增速达 $58.3 \%$ 远超C 2 C的 $12.6 \%$; 移动购物用户增速达 $44.7 \%$, 在网购用户中占比高达 $92.4 \%$, 实现交易规模 2.1 万亿元, 在整体网络购物交易规模中 占比高达 $55 \%$, 较去年增长 21.3 个百分点; 本地生活 020 的市场交易规模增幅高达 $38.4 \%$, 共实 现交易额3352亿元。

近年来，我国农村地区消费潜力的快速增长，刺激阿里、京东、苏宁等电商巨头纷纷进 军农村市场, 在政府各种推动电子商务进农村的利好政策下, 农村电子商务市场发展迅猛。 近年来, 中国网民规模及农村网民规模持续增长, 截至 2016 年 6 月分别达 7.10 亿人和 1.91 亿人, 农村网民的占比也上升至 $26.9 \%$ 。农村电商覆盖面及其市场规模也呈现出逐年递增的态势。以 淘宝为例, 发展淘宝村业已成为建设特色小镇的重要模式, 淘宝网 (含天猫) 的农村地区交易 额占全网的比例持续增长。 ${ }^{6}$ 中国电子商务研究中心发布的《2015年度中国网络零售市场数据 监测报告》称，2015年农村网购市场规模较2014年增长94.3\%，实现交易额高达3530亿元，预 计到2016年将达到约4600亿元。

随着互联网技术的发展以及政府政策层面的支撑， ${ }^{7}$ 以“海淘”为代表的跨境电商企业发 展迅猛, 跨境电商交易快速增。2010-2015年中国跨境电商占进出口贸易额比例一直呈上升趋 势, 未来有望继续上升。阿里研究院《2016中国跨境电商发展报告》指出, 2015年中国跨境 电商占进出口贸易额的比例仅为 $7.6 \%$, 实现的交易额为 2.24 万亿元; 预计到 2017 年该比例将 达到23.1\%，实现的交易额将达到8万亿元，到2020年该比例将达到 $37.6 \%$ 。

近年来，随着移动互联网的发展4G时代已经到来，消费者的时间呈现碎片化趋势，传统 电子商务已经不能很好的满足人们的需求, 我国移动电商快速发展壮大, 交易规模持续增长。 4G时代随着运营商不断推出手机上网优惠政策, 手机用户可以更加经济的享受移动电商方便 快捷的服务，我国手机网民规模及手机上网使用率均有大幅上升。截至2016年6月，中国手机 网民规模较 2010 年增长了 $116.5 \%$, 达到 6.56 亿人, 手机上网使用率较 2015 年底的 $90.1 \%$ 提高了 2.4 个百分点。 2015 年中国移动购物用户规模达到 3.8 亿人, 增速达到 $44.7 \%$, 在网购用户中占 比高达92. 4\%。2015年移动网购市场交易规模的增速为 $123.8 \%$, 远高于中国网络购物整体的增 速 $36.2 \%$ ，实现交易额达 2.1 万亿元。

\subsection{3服务业新业态的发展现状}

随着传统服务业与互联网技术的不断深化融合，新兴服务业态和新型服务模式不断涌现， 现代服务业已经成为支撑我国新常态下经济增长的重要引擎, 在GDP中所占比例越来越大。国 家统计局公布的数据显示，继2013年服务业在GDP中所占比例首次超过了工业，2015年第三季 度占比已经过半。 ${ }^{8}$ 总结现代服务业企业的产品服务模式有以下三种：（1）产品免费，以增 值服务作为收入来源。这类企业的特征是以免费的产品获得客户, 然后根据客户的不同需求 提供增值服务获利, 如腾讯、谷歌、淘宝等。（2）产品收费，提供免费的增值服务。这类企 业通过出售主产品获利, 但会推出一些免费的增值服务吸引保留客户，如联想、惠普等。

\footnotetext{
5 阿里研究院 2014 年发布的消费报告指出, 2012-2014三年间淘宝农村消费占比不断提升, 从2012 年第二季度 的 $7.11 \%$ 上升至 2014 年第一季度的 $9.11 \%$ 。

6据阿里研究院联合阿里农村淘宝事业部共同发布的《农村网络消费研究报告(2015)》报告，截止2015年6月底， 农村淘宝已累计覆盖全国17个省, 建立63个县级服务中心, 建成1803个村点服务站; 淘宝网 (含天猫) 发往农村 地区的订单金额占全网的比例，长从2013年第一季的 $8.65 \%$ ，上升到2015年第一季度的 $9.64 \%$ 。

7 2016年的政府工作报告中涉及跨境电商的表述: 扩大跨境电子商务试点, 支持企业建设一批出口产品 “海外 仓”，促进外贸综合服务企业发展。

8数据来源中投顾问发布的《2016-2020年中国现代服务业深度调研及投资前景预测报告》。
} 
产品与增值服务都收费。以苹果公司为例, 这类企业不仅销售硬件产品, 还吸引用户来购买 各种与主产品相适应的软件。

现代服务业呈现出如下三种新业态：（1）传统服务业的转型升级。例如，在传统旅游业 方面, 在线旅游已经成为资本竞相追逐的热点领域, 2015年我国在线旅游市场交易规模超过 4000 亿元, 较上年增长 $37.5 \%$ 。（2）新兴服务业的创新发展。在旅游、餐饮、交通等诸多传 统领域均推出了体验式服务, 形成服务业新业态。例如, 快递行业推进 “定制、精准和安全” 的体验式服务, “网订店取”、“智能快递箱” 等新型配送模式得到推广。（3）综合类服务 机构及平台的形成发展。例如, 网络巨头阿里巴巴从电商业务起家, 目前已跨足金融、云极 端、团购、地图、传媒、电子信息、娱乐、旅游、零售、教育、社交、浏览器、医药、物流、 在线视频、打车软件等众多领域, 已成为一家综合性服务企业。

\section{3. 互联网经济负面效应的内涵及原因}

\section{1 互联网经济负面效应的内涵界定}

不可否认互联网经济的发展对我国的传统行业改造、产业结构调整升级等方面都起到了 积极作用, 我国GDP中的互联网经济所占比例日益壮大。然而, 伴随着互联网经济而来的 “魏 则西事件”、“饿了么黑心作坊事件” 等不良事件不断发生也是现实存在。在充分肯定成绩 的同时, 更应重视问题的存在, 并积极寻求解决问题的方法, 才能更好的发挥互联网经济的 积极作用, 取得更好的成绩。本文将互联网经济下对消费者、社会环境等方方面面造成的不 良影响统称为互联网经济的负面效应。

\section{2 互联网经济负面效应的原因分析}

伴随互联网经济而生的负面效应层出不穷, 究其原因可总结为如下四点:

（1）政府监管意识不强、监管滞后、监管力度不足。一方面，在互联网经济不断发展的 大背景下, 政府监管和干预职能并未积极表现, 往往在出现了各种互联网经济负面效应之后, 政府才采取极端手段进行临时应急处理。另一方面, 由于互联网具有虚拟性、开放性、跨界 性、传播性和分享性等多种区别于实体联系媒介的特点, 传统的建立在地域、行业基础上的 政府管理体制势必不适应互联网经济下不断产生的新业态的监管需求。例如，2016年《民生 直通车》报道的山东济南一家叫做东领在线的P2P公司老板卷款跑路事件。政府监管不到位、 互联网的虚拟性等因素, 平台的真实性无从考证, 导致此类事件层出不穷, 对互联网金融业 行业的发展造成不良影响。

（2）第三方交易平台监管不到位。很多传统行业的新业态，尤其是服务行业的新形态大 多是在虚拟环境中完成交易, 由于第三方交易平台的监管不到位导致淘宝、网上订餐平台等 交易平台制售假冒伪劣商品事件层出不穷。例如, 央视315晚会曝光的2016年 “饿了么黑心作 坊事件”，该事件中 “饿了么”平台上的商家出现了多种违规现象，对入驻商家的审核严重 缺失, 甚至该平台还引导商家虚构经营地址和实体照片, 默许不符合经营要求的黑心作坊入 驻。

（3）供给方在利益导向下的异化行为。由于互联网的虚拟性、供需双方的信息不对称性 以及 “经济人” 追求效用最大等因素, 处于信息优势的供给方在提供服务或产品过程中过分 追逐自身利益, 出现由价格决定市场供给等异化行为。例如, 魏则西事件中, 涉事医院属于 “莆田系” , 这类医院往往通过百度搜所平台发布信息, 然而百度推广一般是根据费用多少 来决定推广信息的排名, 这就导致所谓的逆向选择。

(4) 需求方安全意识不足。由于互联网的虚拟性、供给方的信息需求方无法确认、需求 方缺乏专业知识, 在高额回报的诱惑下, 需求方往往忽略各种风险和漏洞。例如, 近年来频 发的电信网络诈骗事件, 据2016年《山东新闻联播》报道, 仅上半年, 山东省电信网络诈骗 案件就立案了 10390 起, 其中, 短信计骗和网络诈骗占比近七成, 共造成财产损失 3.86 亿元。 


\section{4. 对策建议}

针对联网经济负面效应产生的原因，我们提出如下几条对策建议:

(1) 明确政府在整个监管体系中的角色定位，完善政府监管体系，及时出台相应的法律 法规。互联网经济时代，互联网不断向金融、物流、教育、医疗等几乎所有行业领域延伸， 新兴业态或新兴行业不断涌现, 政府不可能也做不到面面俱到, 这就需要政府明确自己的角 色定位, 与相关行业或平台相互协作完善监管体系, 及时出台相应的法律法规适应新兴的互 联网业务。尤其是在食品安全、医疗保健等民生领域, 政府更应该出台相关法规, 加强监管的力度及广度, 同 时加重处罚强度。

（2）提高准入门槛，政府敦促第三方交易平台切实履行监管责任，丰富监管手段，创新 监管模式。第三方交易平台根据行业特点、信用状况等科学合理的设定准入门槛, 避免重复 出现 “饿了么黑心作坊事件”。政府通过奖惩结合的方式，强化第三方交易平台的监管意识， 建立一套从源头上防控假冒伪劣商品进入的准入机制, 将登记与监管挂钩。政府强化互联网 治理专业人才的培养, 促使他们参与第三方交易平台的监管工作, 适应层出不穷的新兴行业 及新兴服务模式。

（3）加快信用体系建设，引导供给方不惟结果导向、利益导向论英雄，倡导兼顾利益与 道德、社会责任的互利行为。信用是市场行为与行为主体之间最关键的纽带, 完善信用评价 机制, 严格审查, 将严重失信企业纳入 “黑名单”。一个结果导向型的社会中, 必然会存在 各种违规行为、负面事件，因此要制定有关道德、社会责任、环境保护等方面的评价指标， 引领市场主体在追逐自身利益的同时兼顾过程中的环境保护、社会责任等公众利益。

（4）强化需求方的安全意识，及时在公众平台上推送相关专业领域的基本知识。政府应 适度介绍各类互联网经济下的负面事件，分析其发生的背景原因，提高消费者的安全意识; 倡导各行业专家在公共平台上介绍相关领域的基本知识与风险防控, 加强消费者对新兴领域 的了解，避免落入不法分子的陷阱。

\section{References}

[1] WANG Mingguo. Present situation and problems of online banking in China, The Chinese Banker, vol.5, pp. 63-65,2015.

[2] http://mt.sohu.com/20160501/n447168344.shtm

[3] The Report of Rural Network Consumption 2015.

[4] The Report of China's Internet Financial Development 2016.

[5] 38 times "The Statistics Report of China's Internet Development ".

[6] Yu Shiyang, Tong Nannan, Wang Jiandong. The analysis of negative effects by China's Internet governance "disorder", E-Government, vol.5, pp. 42-46,2016.

[7] Wang Yuhua. Present Situation and Developing Trend of Electronic Commerce in China in 2015, Science and Technology of West China, vol.15, pp. 82-84, 2016.

[8] Yang Wei. The current situation of the development of the Internet financial and regulatory measures under new economic normality, Heilongjiang Finance, vol.6, pp. 16-17, 2016. 